\title{
CATHARINA MOURA E O FEMINISMO NA PARAHYBA DO NORTE
}

Resenha do livro:

MACHADO, Charliton José dos Santos; NUNES, Maria Lúcia da Silva; MENDES, Márcia Cristiane Ferreira. Catharina Moura e o Feminismo na Parahyba do Norte. Fortaleza: UFC, 2013.

Resenha de

Larissa Meira de Vasconcelos

Universidade Federal da Paraíba (UFPB)

Calcada em cuidadosa coleta de fontes, a produção do livro "Catharina Moura e o feminismo na Parahyba do Norte" está intimamente associada ao projeto de pesquisa Educação e educadoras na Paraíba do século XX: práticas, leituras e representações, do Grupo de Estudos e Pesquisas "História, Sociedade e Educação no Brasil" (HISTEDBR-GT/PB), do Programa de Pós-Graduação em Educação da Universidade Federal da Paraíba (PPGE/UFPB). É válido afirmar que os autores Charliton Machado, Lúcia Nunes e Márcia Mendes além de proporem divulgar e analisar as práticas de escrita da advogada e educadora paraibana Catharina Moura, notadamente, o conteúdo da conferência intitulada "Os direitos da mulher", proferida por ela no debate "Universidade Popular" e publicada na íntegra pelo Jornal A União, contribuem, sobremaneira, à História das Mulheres, à História do Feminismo e à História da Educação de gênero na Paraíba.

Seguramente, a obra aponta as potencialidades e entraves na pesquisa histórica com periódicos. Malgrado os jornais já tenham sido consideradas fontes suspeitas, o que justificou, durante décadas, a recusa em aceitá-los como documentos dignos à escrita da história, este suporte comporta em si uma existência polissêmica, própria da sociedade de onde eles provêm. Talvez, seja possível sugerir que a pujança desta fonte esteja justamente em seu caráter fragmentário e parcial, fazendo da realidade um mosaico de verdades possíveis. (CAMPOS, 2012). Por outro lado, as restrições materiais de se trabalhar com periódicos, como afirmam os autores logo na introdução do livro, remetem à desorganização e falta de cuidados na conservação dos acervos públicos da Paraíba, o que, evidentemente, dificulta a pesquisa. É preciso estar atento, ainda, aos motivos que levaram determinadas coleções de jornais a sobreviver à ação do tempo, pois a disponibilidade em arquivo público ou pessoal comporta diferentes sentidos. As indagações sobre quem foi Catharina Moura e qual o seu significado político, portanto, ancoram-se no paradigma indiciário de Ginzburg, ao seguir rastros e pegadas dos testemunhos e práticas do feminino inscritos na Paraíba da Primeira República.

A obra divide-se em 3 capítulos. No primeiro, os autores descrevem uma breve biografia da educadora e trazem à tona, em contraposição ao que propugna o título do capítulo, denominado "Catharina Moura: indícios de uma educadora à frente do seu tempo", o efervescente cenário político e cultural que propiciou a emergência do discurso da paraibana. Sua sólida formação acadêmica iniciada na Escola Normal Oficial, passando pelo Liceu Paraibano, teve como desfecho o bacharelado na Faculdade de Direito de Recife, em 1912, figurando-se como a única mulher a concluir a graduação naquele ano. Exitosa em sua formação jurídica obteve como prêmio uma viagem à Europa, o que muito deve ter corroborado para fortificar suas convicções sobre a legitimidade da luta sufragista. Além de advogada, Catharina Moura atuou como 
professora da Escola Normal da capital da Paraíba, ministrando as cadeiras de Português, Desenho, Francês e História da Civilização.

No contexto das conferências para a Universidade Popular, a província da Paraíba estava sob a gestão do presidente João Pereira de Castro Pinto, um político atrelado às oligarquias locais, indicado à época como um nome de conciliação das elites. Segundo os autores, Castro Pinto foi um homem entusiasta das idéias republicanas tão veiculadas à época e teve seu governo marcado pelo valor que deu às letras. Ao promover o debate em torno de uma Universidade Popular, teria como ambição preparar a Paraíba para a modernidade. Catharina Moura foi a única mulher convidada a proferir uma palestra, em meio a 30 conferências previstas, na ocasião. Assim, apropriadamente, os autores convidam o leitor a indagar-se o quanto o discurso da educadora, de fato, "constituía-se numa voz isolada no cenário da Primeira República na Paraíba e qual interesse intelectual e político em inserir a referida temática no elenco das conferências da Universidade Popular". (MACHADO; NUNES; MENDES, 2013, p. 29).

No segundo capítulo, intitulado "O feminismo de Catharina Moura", a obra discute de que forma e com quais ferramentas a educadora e advogada conquistou espaço na imprensa paraibana. Utilizando-se de sua condição social e intelectual privilegiada, no interior de uma esfera pública eminentemente masculina, Catharina utilizou como tática o tom moderado e o distanciamento em relação às lutas feministas que reunia a militância no Brasil em prol do sufrágio universal. Recusava a alcunha feminista, sem, contudo, deixar de registrar sua admiração pelas mulheres que assumiam essa condição na sociedade, "mulheres sublimes, admiráveis e impávidas aquelas que se arriscam na luta pela emancipação do sexo feminino". (MACHADO; NUNES; MENDES, 2013, p. 35). Ao optar pelo confronto sutil e, por vezes, irônico, a conferencista opõe-se às interpretações jurídicas que entrevia na mulher um sujeito político inferior, tecendo, dessa forma, críticas não apenas ao papel reservado às mulheres na nascente república, mas também ao modelo de participação política, no qual "poucos eleitores eram chamados, casualmente, apenas para homologar as escolhas previamente feitas nos pactos oligárquicos de sucessão do poder, sem, contudo, interferir na administração pública". (MACHADO; NUNES; MENDES, 2013, p. 36). Outra questão enfatizada em sua conferência é a importância da educação como condição primeira à emancipação da mulher no histórico processo da civilização humana. Dessa forma, não bastava conquistar o direito ao voto, mas ter como primazia lograr êxito no acesso à educação.

É interessante notar que o discurso de Catharina Moura valeu-se de táticas largamente empregadas pelo movimento feminista nos iniciais anos da Primeira República, a fim de subverter, para seus próprios fins, uma representação imposta. (SOIHET, 2000). Certeau (1994, p. 100) sugere que as táticas são ações calculadas por aquele que "não tem por lugar senão o do outro e por isso deve jogar com o terreno que lhe é imposto, tal como o organiza a lei de uma força estranha". Logo, embora existam críticas à atuação do movimento sufragista, associando-o a um "feminismo bemcomportado, católico, elegante, 'feminino" (MACEDO, 2003, p.100), reduzindo, dessa forma, a luta e direitos conquistados a uma concessão, quando assim interessou à classe dominante (ALVES, 1980), os autores de "Catharina Moura e o feminismo na Parahyba do Norte" subscrevem a posição de Costa (2006) quando afirmam que os atos políticos do sufragismo não podem ser considerados domesticados, ainda que bem comportados.

Por sua vez, o terceiro capítulo, designado "Repercussões da Conferência 'Direitos da Mulher" traz uma interessante compilação de comentários, também publicados no Jornal A União, órgão oficial do Estado, em resposta à conferência de 
Catharina Moura. As ressonâncias igualam-se pelas críticas ácidas ao posicionamento da educadora. Em todos os comentários são repetidos argumentos que reforçam a suposta natureza feminina frágil e passional, incompatível com as demandas políticas da vida pública. Ainda apelam estrategicamente para a beleza, o amor e a superioridade da alma feminina em prol da defesa à permanência da mulher nas suas funções de mãe, esposa e rainha do lar.

Enfim, "Catharina Moura e o feminismo na Parahyba do Norte" torna-se ainda mais relevante porque reproduz todas as fontes pesquisadas na íntegra, o que permite ao leitor revisitá-las e entrecruzá-las com outros olhares, lançando provocações e ampliando o leque de problematizações possíveis. A importância de Catharina Moura, por sua vez, não pode se restringir à defesa desta conferência como inaugural, como a "primeira manifestação feminista escrita em solo paraibano". (MACHADO; NUNES; MENDES, 2013, p. 56). Por conseguinte, é necessário descentrar o debate do ponto de vista da "origem". Não se trata de buscar um momento solene de fundação (FAVACHO, 2010), tampouco perfazer uma ode à personagem pesquisada, mas reconhecer que esse documento se configura como uma ruptura nas formas de viver e pensar as relações de Gênero, na Paraíba, dentro das primeiras décadas do século XX.

\section{Referências}

ALVES, Branca Moreira. Ideologia \& feminismo. A luta da mulher pelo voto no Brasil. Petrópolis: Vozes, 1980.

CAMPOS, Raquel Discini de. No rastro de velhos jornais: considerações sobre a utilização da imprensa não pedagógica como fonte para a escrita da história da educação. In: Revista Brasileira de História da Educação. Campinas-SP, v. 12, n. 1 (28), pp. 45-70, jan./abr. 2012. Disponível em: <http://www.rbhe.sbhe.org.br/index.php/rbhe/article/view/320 >. Acesso em: 29/09/2012.

CERTEAU, Michel de. A invenção do cotidiano: artes de fazer. Tradução de Ephraim Ferreira Alves. Petrópolis: Vozes, 1994.

COSTA, Suely Gomes. Um estimulante encontro com Michel de Certeau: o feminismo tático de Bertha Lutz. Cadernos Pagu, N²7, Campinas: 2006, p. 449-454.

FAVACHO, André Marcio Picanço. Rir das solenidades da origem: ou o inesperado da pesquisa em educação. In: Revista Educação e Pesquisa, São Paulo, v. 36, n.2, maio/ago. 2010, pp. 555-569. Disponível em: < http://www.scielo.br/pdf/ep/v36n2/a09v36n2.pdf>. Acesso em: 16/09/2013.

MACEDO, E. D. V. Uma luta justa... e elegante: os feminismos conflituantes de Bertha Lutz e Maria Lacerda de Moura na década de 1920. In: Revista do Núcleo Transdisciplinar de Estudos de Gênero. Niterói: EdUFF, 2003. v. 3, n. 2, p. 34-67

MACHADO, Charliton José dos Santos; NUNES, Maria Lúcia da Silva; MENDES, Márcia Cristiane Ferreira. Catharina Moura e o Feminismo na Parahyba do Norte. Fortaleza: UFC, 2013.

SOIHET, Rachel. A pedagogia da conquista do espaço público pelas mulheres e a militância feminista de Bertha Lutz. In: Revista Brasileira de Educação. Set./ Out./ Nov./ Dez. 2000, nº15, p. 97-117. 